\title{
Arithmetic relaxation time of induced polarization fractal dimension for characterizing Shajara Reservoirs of the Shajara Formation
}

Prof. Khalid Elyas Mohamed Elameen AlKhidir

${ }^{1}$ Department of Petroleum and Natural Gas Engineering, King Saud University, Riyadh, 800/11421, Saudi Arabia

\begin{abstract}
Aim: Sandstone samples were collected from the surface type section of the Shajara Formation of the Permo-Carboniferous Unayzah Group for detailed reservoir characterization. Capillary pressure experiment was performed to contact porosity and permeability was derived from the Data. Arithmetic relaxation time of induced polarization was calculated from the distribution of Permeability and the fractal dimension was calculated from the relationship between wetting phase saturation and Arithmetic relaxation time of induced polarization. In addition to field observation and obtained results of fractal dimension values, the Shajara reservoirs of the Shajara Formation of the permo-Carboniferous Unayzah Group were divided here into three fractal dimension units. The Units from base to top are: Lower, Middle, and Upper Shajara Arithmetic Relaxation Time Fractal dimension Units. It was also reported that the obtained fractal dimension speeds with increasing permeability and relaxation time due to an increase in pore connectivity.
\end{abstract}

Keywords: Shajara Formation; Shajara Reservoirs; Permeability; fractal dimension

\section{Introduction}

Laboratory study of induced polarization in sandstone rocks with varying salinity and shalyness was investigated by (Schoeppel et al. 1966). An increase of induced polarization effect with increasing permeability, increasing porosity, and decreasing shalyness was examined by (Schoeppel et al. 1966). An increase of permeability with increasing geometric and arithmetic induced polarization relaxation time and increasing porosity was confirmed by (Maosong et al. 2004).

A new integrated model with relaxation time spectra, porosity and formation factor was proposed to predict permeability was recognized by (Liu et al. 2014). Bimodal Pore Size behavior of the Shajara Formation reservoirs of the permo-carboniferous Unayzah group was investigated by (Al-Khidir et al. 2011). Subdivision of the Shajara reservoirs into three units based on thermody-namic fractal dimension approach and 3-D fractal geometry model of mercury intrusion technique was reported by (Al-Khidir et al. 2013). Classification of Shajara reservoirs into three units based on nuclear magnetic resonance relaxation time fractal dimension was investigated by Al-Khidir 2017. The obtained units from base to top are: Lower Shajara Nuclear Magnetic Resonance relaxation Time Fractal Dimension unit, Middle Shajara Nuclear Magnetic Resonance relaxation Time Fractal Dimension unit, Upper Shajara Nuclear Magnetic Resonance relaxation Time Fractal Dimension unit.

\section{Materials and Methods}

Porosity was measured on collected sandstone samples from the surface type section of the Shajara formation of the permo-carboniferous Unayzah Group. Permeability was calculated from the measured capillary pressure data by mercury injection porosimetry method. The objective of this manuscript is to calculate the Arithmetic relaxation time of induced polarization from the permeability distribution and to calculate the fractal dimension from the relaxation time.

Copyright (C) 2018 Prof. Khalid Elyas Mohamed Elameen AlKhidir.

doi: $10.18063 /$ nn.v2i1.363

This is an open-access article distributed under the terms of the Creative Commons Attribution Unported License

(http://creativecommons.org/licenses/by-nc/4.0/), which permits unrestricted use, distribution, and reproduction in any medium, provided the original work is properly cited. 


\section{Results and Discussion}

Based on field observation the Shajara Reservoirs of the Shajara Formation of the Permo-Carboniferous Unayzah Group were divided here into three units as described in Figure1.These units from base to top are: Lower Shajara Reservoir, Middle Shajara reservoir, and Upper Shajara Reservoir. Their acquired results of the arithmetic relaxation time fractal dimension of induced polarization are displayed in Table 1. Based on the attained results it was found the maximum value of the fractal dimension was found to be 2.7872 assigned to sample SJ13 from the Upper Shajara Reservoir as verified in Table 1. Whereas the minimum value of the fractal dimension was reported from sample SJ3 from the Lower Shajara reservoir as displayed in Table1.The arithmetic relaxation time induced polarization fractal dimensions were observed to increase with increasing permeability as shown in Table1 owing to the possibility of having interconnected channels. The Lower Shajara reservoir was denoted by four sandstone samples out of six, label as SJ1, SJ2, SJ3 and SJ4 as confirmed in (Figure1). Their geometric fractal dimension values are shown in (Table 1) and their slopes (3-fractal dimension) were displayed in Figure 2, Figure 3, Figure 4, and Figure 5 respectively. As we proceed from sample SJ2 to SJ3 a pronounced re-duction in permeability due to compaction was reported from 1955 md to $56 \mathrm{md}$ which reflects decrease in arithmetic relaxation time fractal dimension from 2.7748 to 2.4379 as specified in (Table 1) and an increase in slope from 0.2252 to 0.5621 as shown in Figure 3 and Figure 4. Again decrease in slope and increase of permeability was recorded as we proceed from sample SJ3 to sample SJ4 whose arithmetic fractal dimension value was found to be 2.6843 as described in Table 1 .

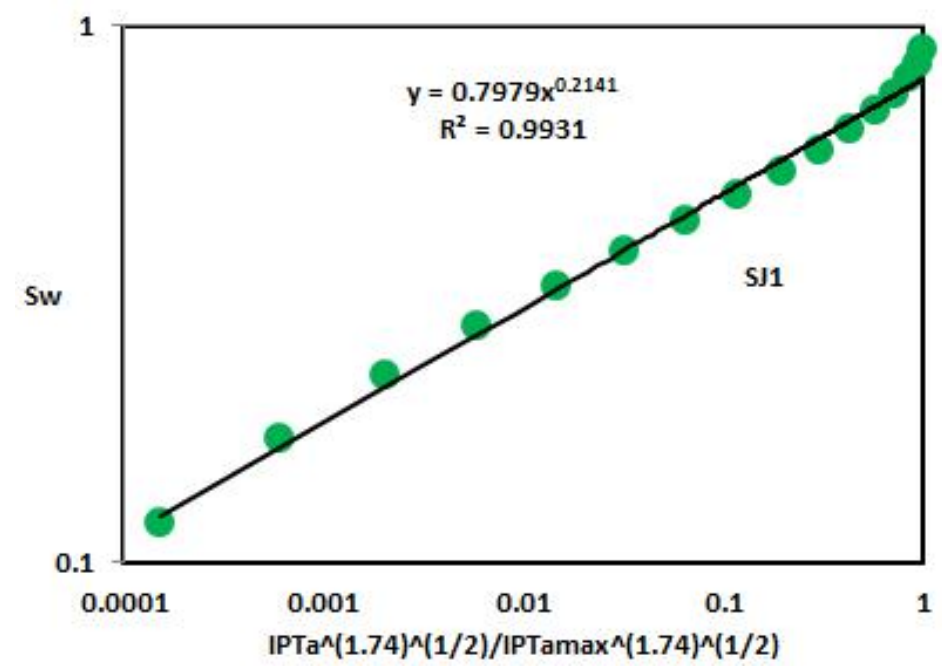

Figure 2; Arithmetic relaxation time of induced polarization versus wetting phase saturation of sample SJ1

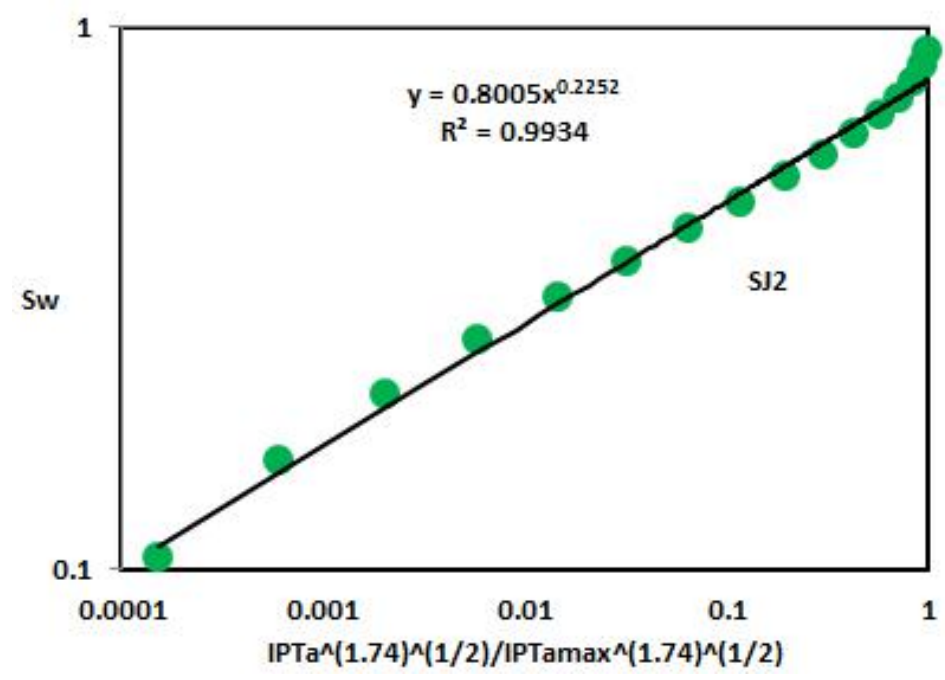

Figure 3; Arithmetic relaxation time of induced polarization versus wetting phase saturation of sample SJ2 


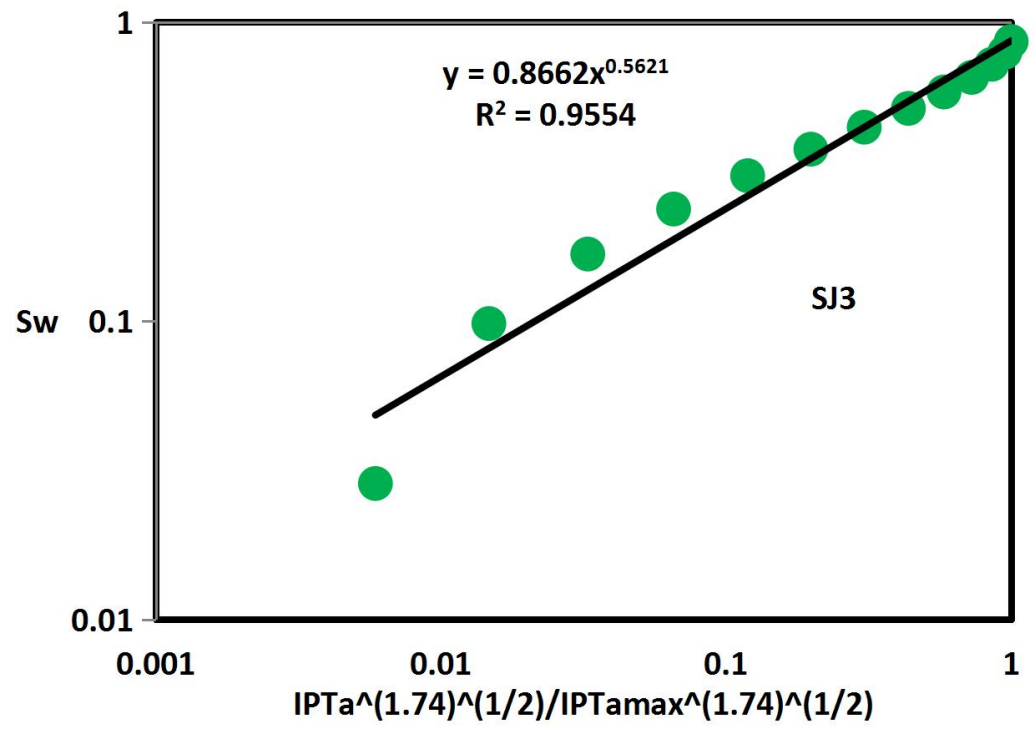

Figure 4; Arithmetic relaxation time of induced polarization versus wetting phase saturation of sample SJ3

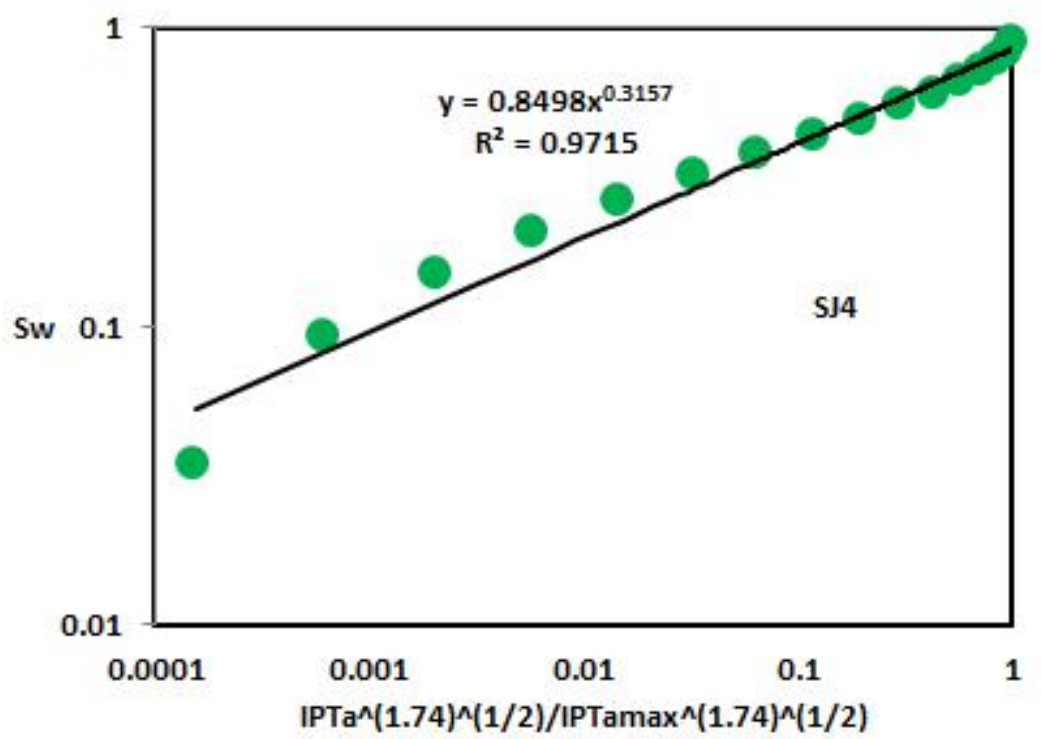

Figure 5; Arithmetic relaxation time of induced polarization versus wetting phase saturation of sample SJ4 


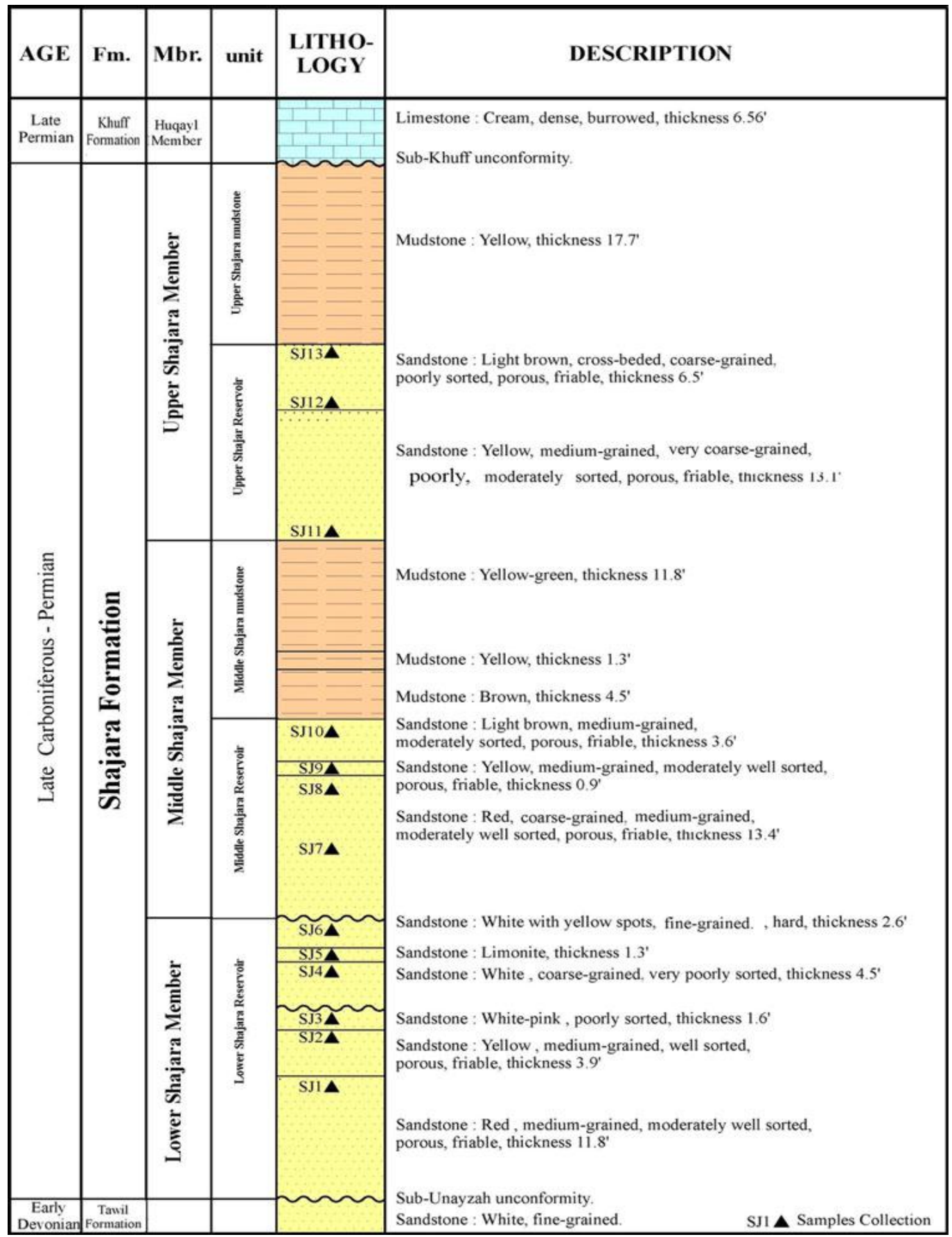

Figure 1; Stratigraphic column of the type section of the Permo-carboniferous Shajara Formation of the Unayzah Group, Wadi Shajara, Qusayba area, al Qassim district, Saudi Arabia, N 26_52 17.4, E 43_36 18

In contrast, the Middle Shajara reservoir was separated from the Lower Shajara reservoir by an unconformity surface as shown in (Figure 1). It was designated by three sam-ples out of four, namely SJ7, SJ8, and SJ9 as illustrated in (Figure1). Their arithmetic relaxation time induced polarization fractal dimensions values were delineated in (Table 1) and their slopes (3-fractal dimension) were illustrated in Figure 6, Figure 7, and figure 8 respectively .Their fractal dimensions values are higher than those of samples SJ3 and SJ4 from the Lower Shajara Reservoir due to an increase in their permeabilities as explained in (Table 1). 


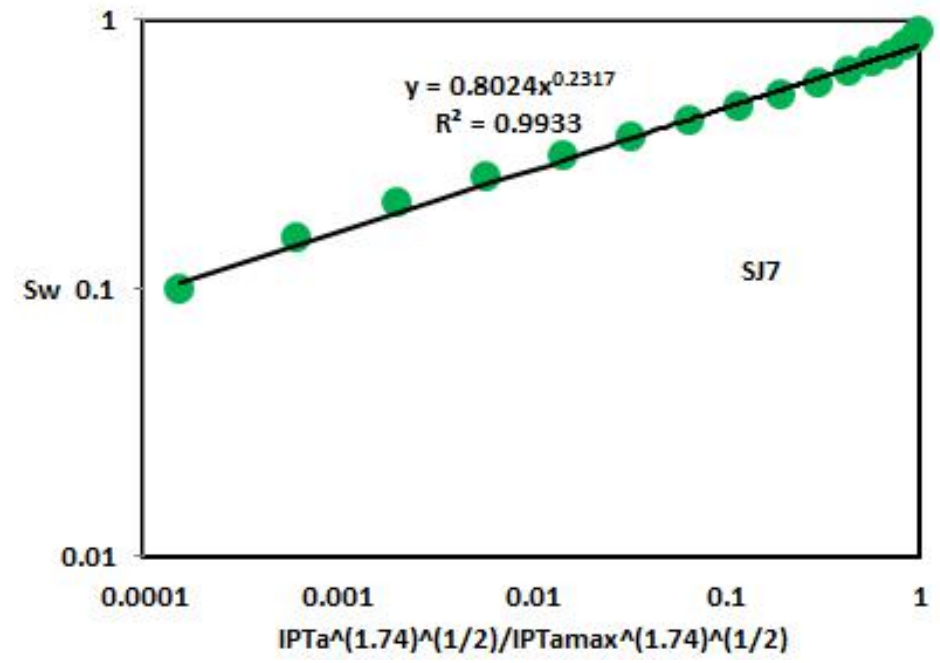

Figure 6; Arithmetic relaxation time of induced polarization versus wetting phase saturation of sample SJ7

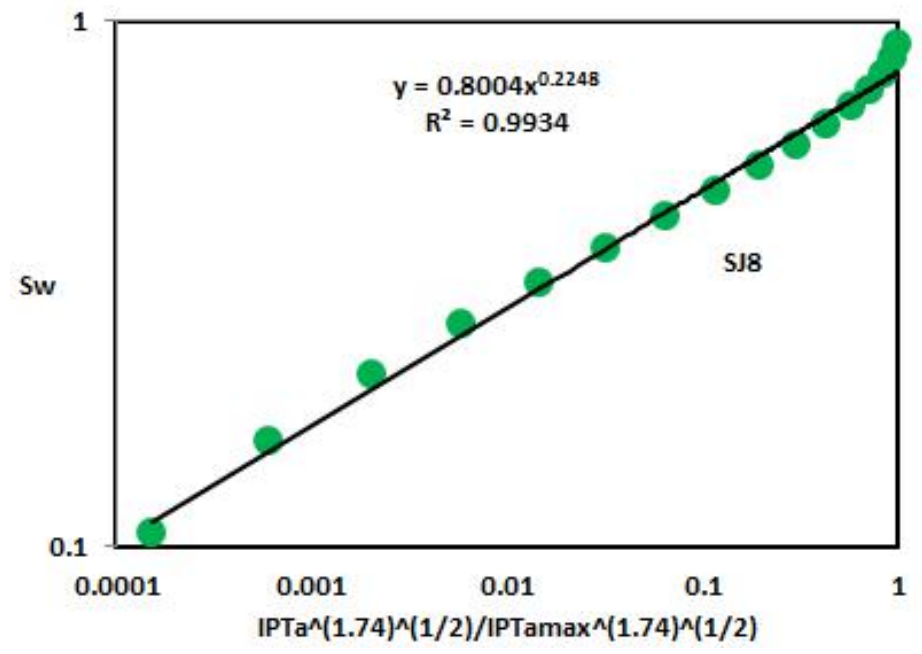

Figure 7; Arithmetic relaxation time of induced polarization versus wetting phase saturation of sample SJ8

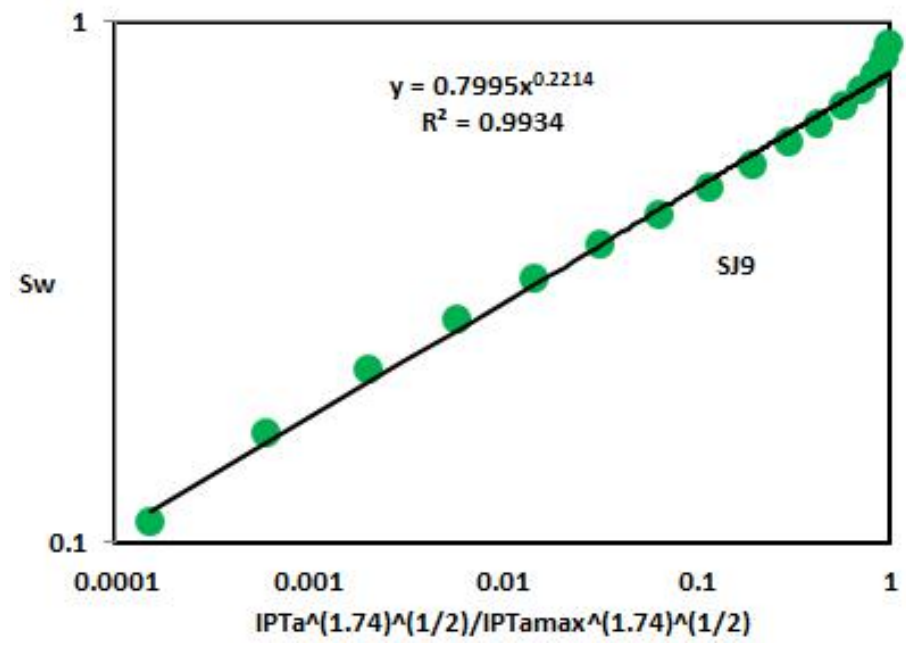

Figure 8; Arithmetic relaxation time of induced polarization versus wetting phase saturation of sample SJ9

On the other hand, the Upper Shajara reservoir was separated from the underlying Middle Shajara reservoir by yellow- green mudstone as revealed in (Figure1). It is defined by three sandstone sam-ples so called SJ11, SJ12, SJ13 as explained in (Table1) and Figure 9, Figure 10, and Figure 11. 


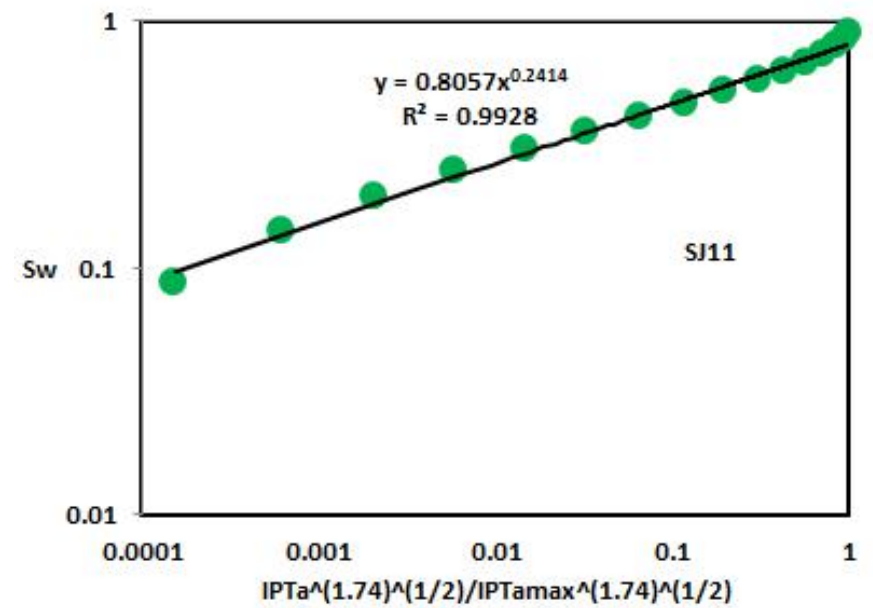

Figure 9; Arithmetic relaxation time of induced polarization versus wetting phase saturation of sample SJ11

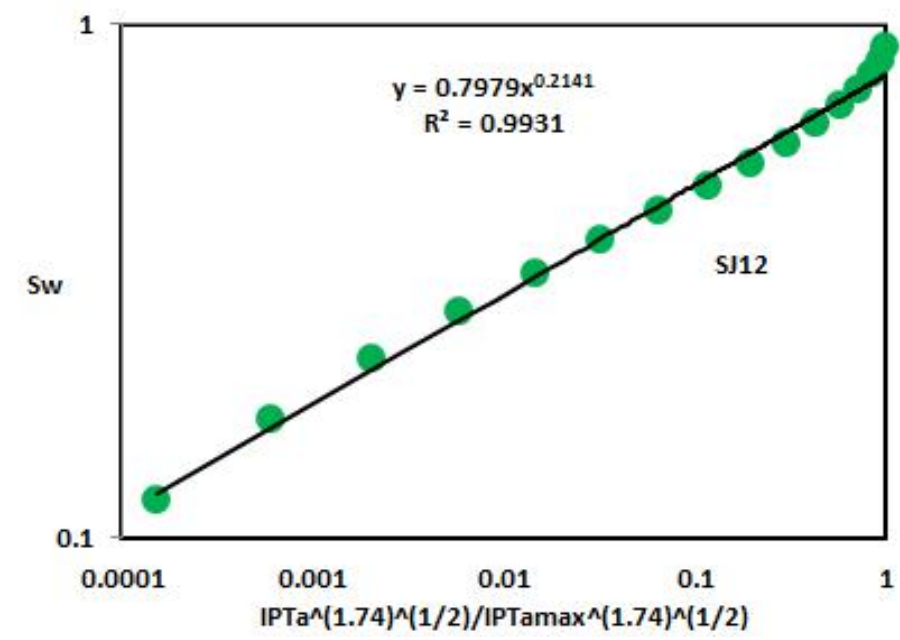

Figure 10; Arithmetic relaxation time of induced polarization versus wetting phase saturation of sample SJ12

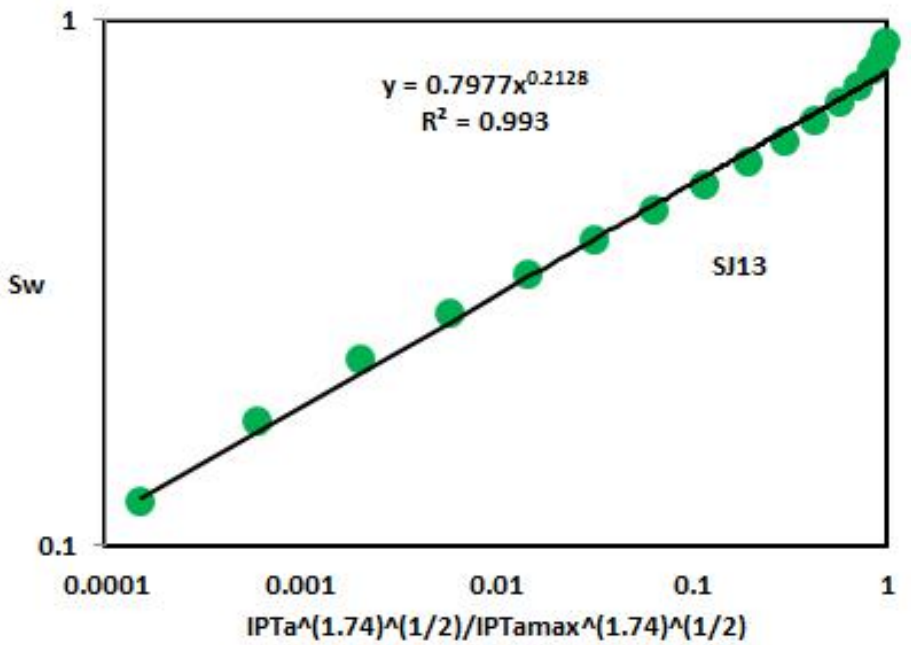

Figure 11; Arithmetic relaxation time of induced polarization versus wetting phase saturation of sample SJ13

Moreover, their arithmetic relaxation time fractal dimension values are also higher than those of sample SJ3 and SJ4 from the Lower Shajara Reservoir due to an increase in their permeabilities as clarified in (Table 1). 


\begin{tabular}{|c|c|c|c|c|c|}
\hline Reservoirs & & Sample & Porosity \% & Permeability mD & $\begin{array}{l}\text { Arithmetic relaxation } \\
\text { time fractal dimension }\end{array}$ \\
\hline \multirow{3}{*}{$\begin{array}{l}\text { Upper } \\
\text { Reservoir }\end{array}$} & \multirow{3}{*}{ Shajara } & SJ13 & 25 & 973 & 2.7872 \\
\hline & & SJ12 & 28 & 1440 & 2.7859 \\
\hline & & SJ11 & 36 & 1197 & 2.7586 \\
\hline \multirow{3}{*}{$\begin{array}{l}\text { Middle } \\
\text { Reservoir }\end{array}$} & \multirow{3}{*}{ Shajara } & SJ9 & 31 & 1394 & 2.7786 \\
\hline & & SJ8 & 32 & 1344 & 2.7752 \\
\hline & & SJ7 & 35 & 1472 & 2.7683 \\
\hline \multirow{4}{*}{$\begin{array}{l}\text { Lower } \\
\text { Reservoir }\end{array}$} & \multirow{4}{*}{ Shajara } & SJ4 & 30 & 176 & 2.6843 \\
\hline & & $\mathrm{SJ} 3$ & 34 & 56 & 2.4379 \\
\hline & & $\mathrm{SJ} 2$ & 35 & 1955 & 2.7748 \\
\hline & & SJ1 & 25 & 1680 & 2.7889 \\
\hline
\end{tabular}

Table1: Petrophysical properties of the three Shajara reservoirs of the Shajara Formation with their Arithmetic relaxation time fractal dimension values.

Overall a plot of fractal dimension versus permeability (Figure 12) reveals three permeable zones which confirm the occurrence of the three Shajara reservoirs of the constructed stratigraphic column. The higher permeable zone with permeability $973 \mathrm{mD}$ and above and fractal dimension 2.7586 and above (Figure 12) belongs to Upper Shajara reservoir, Middle Shajara Reservoir, and samples SJ1 and SJ2 from the Lower Shajara Reservoir. The Moderate permeable zone with fractal dimension 2.6843 and permeability $176 \mathrm{mD}$ (Figure 12) corresponds to sample SJ4 from the Lower Shajara reservoir. The lower permeable zone with fractal dimension 2.4379 and permeability $56 \mathrm{mD}$ (Figure 12) assigns to sample SJ3 from the Lower Shajara reservoir. Such variation in fractal dimension and permeability will reflect heterogeneity of the Shajara reservoirs.

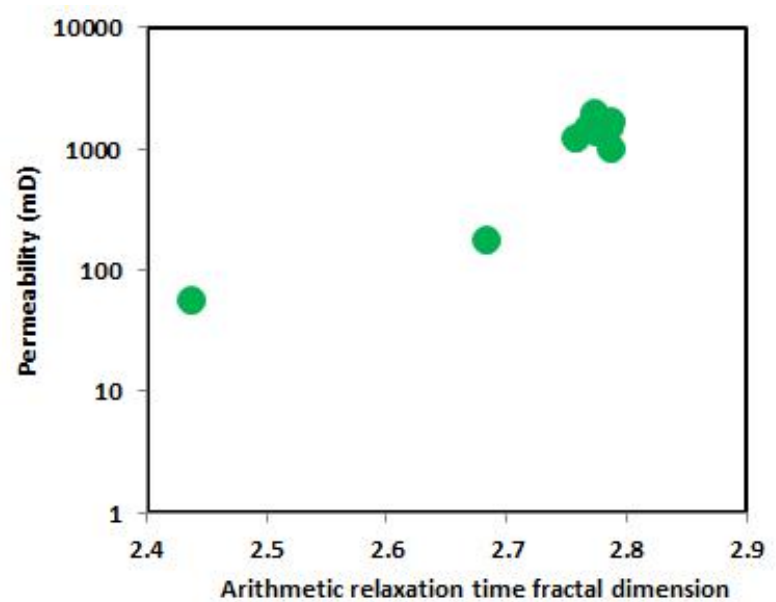

Figure 12; Arithmetic relaxation time of induced polarization fractal dimension versus permeability showing the three permeable zones of the Shajara reservoirs of the Shajara formation

\section{Conclusion}

4.1 The sandstones of the Shajara Reservoirs of the Shajara formation of the permo-Carboniferous Unayzah group were divided here into three units. Lower Shajara Reservoir, Middle Shajara Reservoir, and Upper Shajara Reservoir.

4.2 The three Shajara reservoirs were confirmed by fractal dimension. These units from base to top are: Lower Shajara arithmetic Relaxation time Fractal dimension Unit, Middle Shajara Arithmetic Relaxation Time Fractal Dimension Unit, and Upper Shajara Arithmetic Relaxation time Fractal Dimension Unit.

4.3 The fractal dimension was found to increase with increasing grain size and permeability. 


\section{Acknowledgements}

The author would like to thank King Saud University for their supports.

\section{References}

1. Schoeppel RJ, Thrasher JE. Laboratory study of induced polarizationin sandstone rocks with varying salinity and shalyness, SPWLA 7th Annual Logging Symposium 1966; 5:9-11.

2. Maosong T, Weinan W, Li L, et al. Estimation of permeability of shaly sand reservoir from induced polarization relaxation time spectra. J. Petrol. Sci. Eng 2004; 45: (1-2) 1-10.

3. Liu X, Kong Li, Zhang P, et al. Permeability estimation using relaxation time spectra derived from differential evolution inversion. J. Geophys. Eng 2014; 11: 1-8.

4. Al-Khidir KE, Al-Laboun A, Al-Qurishi A, et al. Bi ᄀmodal pore size behavior of the Shajara Formation Reservoirs of the Permo-Carboniferous Unayzah Group, Saudi Arabia. J Petrol Explor Prod Technol 2011; 1(1): 1-9. https://link.springer.com/article/10.1007/s13202-011-0007-5

5. Al-Khidir KE, Benzagouta M, Al-Qurishi A, et al. Charac $\neg$ terization of heterogeneity of the Shajara Reservoirs of the Shajara Formation of the Permo-Carboniferous Unayzah Group. Arab J Geosci.Arabian 2013; 6(10): 3989-3995. https://link.springer.com/article/10.1007\%2Fs12517-012-0656-9

6. Al-Khidir. Nuclear magnetic resonance as diagnostic parameter for reservoir characterization. Archives of petroleum and Environment biotechnology 2017.

https://gavinpublishers.com/journals/articleprocedureview/Nuclear-magnetic-resonance-relaxation-time-as-a-diagn ostic-parameter-for-reservoir-characterization 